\title{
Overdiagnosis in pediatric practice
}

For many decades now, medicine has suffered a progressive downturn in one of its main pillars: humanism. Undoubtedly, this pillar is indispensable in every action taken by physicians. Humanism also encompasses ethics, which every physician should maintain at all times in every activity carried out, both in relation to medical care and any other activity performed by them.

On the other side, in the first years after World War II, especially in the 1950s, a sharp growth was achieved in another pillar of medicine: science. Investigations yielded increasingly better and greater results, which progressively allowed science to grow and become what it is today. Even with the multiple improvements achieved by science in relation to most health conditions, it is worth noting that it has slowly displaced humanism; in addition to this, economic interests have been behind investigations, some of which have not been adequate.

The number of drug-related studies also increased progressively. As years went by, medication use became more common; most drugs are effective, while others may pose risks and damages.

The third pillar is technology, which has greatly influenced medicine, based on the continuing technological development that has now turned into an overwhelming progress. A frequent use of technology has led physicians to become increasingly subdued by it. Such advances also reached people, who started believing that technology would improve everything, thus also leading to the greater delusion that it would help medicine to solve all of its problems.

This brief summary of the most salient aspects is in part also related to the fact that physicians excessively make a diagnosis that actually does not exist.

In general, overdiagnosis in children entails telling the parents that their child may have a disease. This is especially the case of children attending outpatient offices, although it may also take place in those admitted to a hospital.

It usually leads physicians to order several tests, including $X$-rays, computed tomography (CT) scans, and others studies that are completely unnecessary and may usually result in a bigger damage. Exposure to an intense ionizing radiation from $\mathrm{CT}$ scans has been, for several years, one of the greatest risks, especially in children, mostly in their early childhood and adolescence. This is a serious situation that pediatricians should take into account at all times because radiation is extremely harmful for children since they are more sensitive than adults; therefore, it is really important to protect them.

An inadequate exposure to radiation in children has been a topic of discussion ever since CT scans were introduced in medicine, and for several years, they were done mostly in patients admitted to the emergency department with a traumatic brain injury or potential appendicitis. After several years of using CT scans in children, studies were published that determined that patients who had been exposed to ionizing radiation had four times more risks of cancer, especially leukemia and brain tumors. ${ }^{1,2}$

This indicates that, in those years, pediatricians, especially those working at emergency departments, typically tended to overdiagnosis, because after a clinical examination, they would request several tests, including CT scans, even when the child was well. These risks decreased sharply in recent years due to the awareness of the severe damage caused by radiation. In addition, when it is actually necessary to obtain a diagnostic image in a child, an ultrasound is considered more adequate and, if not effective, a magnetic resonance imaging should be ordered because it does not involve radiation. Likewise, it is worth noting that to prevent such risk, many countries launched several campaigns to eliminate ionizing radiation from imaging tests in pediatrics. ${ }^{3}$

Overdiagnosis in pediatric care is less frequent, approximately $10 \%$ of that observed in adults. However, the damage in children may be even worse due to several disorders that are caused by the physician, not by a disease. For example, when pediatricians order an unnecessary drug that may lead to a potentially severe risk due to a diagnostic error. A very common situation is when physicians prescribe antibiotics in children with a common cold, rhinitis, and catarrh, knowing that almost $90 \%$ of these cases are viral. The US Centers for Disease Control and Prevention (CDC) have reported that this problem reaches an alarmingly high percentage, approximately $50 \%$ of prescribed antibiotics are unnecessary, and this occurs with inpatients 
and outpatients alike. Other data from the CDC indicate that four out of ten children seen at a doctor's office for a common cold receive antibiotics.

A study published a few years ago $\mathrm{o}^{4}$ indicated that $57 \%$ of children seen at a doctor's office due to an acute upper respiratory infection were prescribed antibiotics.

Such inadequate behavior of antibiotic misuse in children may frequently lead to a higher development of antibiotic resistance. This is a severe problem that has been observed in most countries and accounts for a major damage worldwide.

As pointed out by Dr. Moyer, ${ }^{5}$ such behavior among physicians of prescribing inadequate medications in children is causing an increasingly greater evil, with such damage leading to the "medicalization" of patients. In addition, an inadequate excessive treatment in children remarkably leads to higher medications costs faced by parents.

Overdiagnosis usually leads to errors, and this has also been due to the scarce time that pediatricians take to see their patients and their parents. Currently, in many countries, an office visit lasts less than 10 minutes, which results not only in excessive orders for tests and imaging studies, but also in physician's mistakes due to a lack of knowledge. This is ironic. Physicians say that they have no time to see patients and think as part of their routine practice, but that is the moment when thinking deeply is more urgent than ever. Such cognitive problem (not knowing that you do not know) makes physicians believe that they have made an adequate diagnosis or the right decision, but that is not the case. ${ }^{6}$

This is common in medical practice because, in the current field of medicine, health care providers do not accept or tolerate uncertainty, which is a critical attitude that physicians should have. If they take correct actions in complex situations, uncertainty will allow pediatricians to reflect on which would be a more adequate option before making an incorrect decision.
In order to reduce overdiagnosis and errors, physicians should have enough knowledge to develop an adequate valuable result and, thus, be sure that children will not develop any disorder or adverse event.

To conclude, I would like to note a magnificent concept by William Silverman in his publication in Pediatrics ${ }^{7}$ called Compassion or Opportunism? The article opens with: How can we draw a line between what we know and what we do? Do we know enough about the medical and social consequences of our interventions to proceed confidently? Our ability to restrict ourselves should be proportionate to the power we have.

José María Ceriani Cernadas, M.D. Editor

http: / / dx.doi.org/10.5546/ aap.2020.eng.82

To cite: Ceriani Cernadas JM. Overdiagnosis in pediatric practice. Arch Argent Pediatr 2020;118(2):82-83.

\section{REFERENCES}

1. Pearce MS, Salotti JA, Little MP, et al. Radiation exposure from CT scans in childhood and subsequent risk of leukaemia and brain tumours: a retrospective cohort study, The Lancet, Early Online Publication, (2012)

2. Rollins MD, Barnhart DC, Greenberg RA, et al. Neurologically intact children with an isolated skull fracture may be safely discharged after brief observation. J Pediatr Surg 2011;46(7):1342-6

3. Morgan RK, Kotagal M, Adam BG. Campaigns Against Ionizing Radiation and changed Practice Patterns for Imaging Use in Pediatric Appendicitis. JAMA Pediatr. Published online June 22, 2015.

4. Kronman MP, Zhou C, Mangione-Smith R. Bacterial prevalence and antimicrobial prescribing trends for acute respiratory tract infections. Pediatrics. 2014 Oct;134 (4):e 956-65.

5. Moyer VA. Sobrediagnóstico: “Un mal que daña a nuestros niños". Arch Argent Pediatr 2018;116 (6):426-429

6. Obermeyer Z, Lee TH. The complexity of medicine now exceeds the capacity of the human mind. NEJM, Perspective September 28, 2017.

7. Silverman W. Compasión u oportunismo.Pediatrics, $2004 ; 113 ; 402$ 